\title{
Edge Odd Graceful Labeling for Different Paths using Padavon Sequence
}

\author{
S. Uma Maheswari \\ Assistant Professor, Department of Mathematics \\ CMS College of Science \& Commerce, Coimbatore-641049 \\ Tamilnadu, India
}

\begin{abstract}
The even graceful labeling of a graph $\mathrm{G}$ with q edges means that there is an injection $f: V(G)$ to $\{0,1,1,1,2, \ldots, 2 q+i / i=1$ to $\mathrm{n}$ ) such that when each edge uv is assigned the label $\mid \mathrm{f}(\mathrm{u})-$ $\mathrm{f}(\mathrm{v}) \mid$ the resulting edge labels are $\{1,3,5, \ldots, 2 \mathrm{q}-1\}$. A graph which admits an edge odd graceful labeling is called an edgeodd graceful graph. In this paper, the edge odd gracefulness of paths $\mathrm{p}_{1}, \mathrm{p}_{2}, \mathrm{p}_{3, \ldots}, \mathrm{p}_{12}$ is obtained.
\end{abstract}

\section{Keywords}

Padavon sequence, vertex labeling, edge labeling, graceful labeling, odd graceful labeling, edge odd graceful labeling.

\section{INTRODUCTION}

By a graph, we mean a finite undirected graph without loops or multiple edges. A path on $n$ vertices is denoted by $P_{n}$. Graph labeling, where the vertices are assigned certain values subject to some conditions, have often motivated by practical problems. In the last five decades, enormous work has been done on this subject[2].

A study of graceful graphs and graceful labeling methods was introduced by Rosa[4]. Rosa defined a $\beta$-valuation of a graph $\mathrm{G}$ with $\mathrm{q}$ edges an injection from the vertices of $\mathrm{G}$ to the set $\{0,1, \ldots, \mathrm{q}\}$ such that when each edge uv is assigned the label $|\mathrm{f}(\mathrm{u})-\mathrm{f}(\mathrm{v})|$, the resulting edges are distinct. $\beta$-valuation is a function that produces graceful labeling. However the term graceful labeling was not used until Golomb studied such labeling several years later[3].

\section{DEFINITIONS.}

Defn 2.1: Graceful graph: A function $f$ of a graph $G$ is called a graceful labeling with $\mathrm{m}$ edges, if $\mathrm{f}$ is an injection from the vertex set of $\mathrm{G}$ to the set $\{0,1, \ldots, \mathrm{m}\}$ such that when each edge $\mathrm{uv}$ is assigned the label $|\mathrm{f}(\mathrm{u})-\mathrm{f}(\mathrm{v})|$ and the resulting labels are distinct. Then the graph $\mathrm{G}$ is graceful.

Defn 2.2: Path :A path in a graph is a sequence of vertices such that from each of its vertices there is an edge to the next vertex in the sequence. The first vertex is called the start vertex and the last vertex is called the end or terminal vertices of the path and the other vertices in the path are internal vertices.

Defn 2.3:Edge-odd graceful graph: The edge odd graceful labeling of a graph $\mathrm{G}$ with $\mathrm{q}$ edges means that there is an injection $\mathrm{f}: \mathrm{V}(\mathrm{G})$ to $\{0,1,1,1,2, \ldots, 2 \mathrm{q}+\mathrm{i} / \mathrm{i}=1$ to $\mathrm{n}\}$ such that when each edge uv is assigned the label $|f(u)-f(v)|$ the resulting edge labels are $\{1,3,5, \ldots, 2 \mathrm{q}-1\}$. A graph which admits an edge odd graceful labeling is called an edge odd graceful graph.

Defn 2.4:Padavon sequence:
The padavon sequence is the sequence of integers $\mathrm{P}(\mathrm{n})$ defined by the initial values $\mathrm{P}(0)=\mathrm{P}(1)=\mathrm{P}(2)=1$, and the recurrence relation

$$
P(n)=P(n-2)+P(n-3) .
$$

The first few values of $\mathrm{P}(\mathrm{n})$ are $1,1,1,2,2,3,4,5,7$, $9,12,16,21,28,37,49,65,86,114,151,200,265,351,465$, $616, \ldots$

\section{VARIOUS EDGE- ODD GRACEFUL LABELING: \\ 3.1 Edge-odd gracefulness of path $P_{2}$ :}

Theorem 1: $P_{n}$ is edge-odd graceful for every integer $n \geq 2$.

Proof:

Let $\mathrm{V}\left(\mathrm{P}_{2}\right)=\left\{\mathrm{u}_{1}, \mathrm{u}_{2}\right\}$ where $\mathrm{V}\left(\mathrm{P}_{2}\right)$ is the vertex set of the path $\mathrm{P}_{2}$. For every vertex $\mathrm{u}_{\mathrm{i}}$, the edge odd graceful labeling functions $\mathrm{f}\left(\mathrm{u}_{\mathrm{i}}\right)$ is defined as follows.

$$
\mathrm{f}\left(\mathrm{u}_{1}\right)=0 ; \mathrm{f}\left(\mathrm{u}_{2}\right)=\mathrm{q}
$$

The edge labeling function $\mathrm{f}^{*}$ is defined as follows.

$$
f^{*}\left(\mathrm{u}_{1} \mathrm{u}_{2}\right)=\mathrm{q}
$$

Figure 1 shows the method of edge odd graceful labeling of the path $\mathrm{P}_{2}$.

This completes the proof.

$$
1
$$

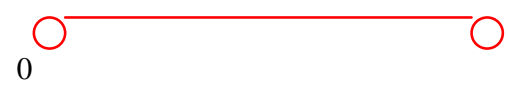

Fig 1

Theorem 2: $P_{n}$ is edge odd graceful for every integer $n \geq 2$.

Proof:

Let $\mathrm{V}\left(\mathrm{P}_{3}\right)=\left\{\mathrm{u}_{1}, \mathrm{u}_{2}, \mathrm{u}_{3}\right\}$ where $\mathrm{V}\left(\mathrm{P}_{3}\right)$ is the vertex set of the path $P_{3}$. For every vertex $u_{i}$, the edge odd graceful labeling functions $f\left(u_{i}\right)$ is defined as follows.

$$
\mathrm{f}\left(\mathrm{u}_{1}\right)=0 ; \mathrm{f}\left(\mathrm{u}_{2}\right)=\mathrm{q}-1 ; \mathrm{f}\left(\mathrm{u}_{3}\right)=\mathrm{q}
$$

The edge labeling function $\mathrm{f}^{*}$ is defined as follows. 


$$
f^{*}\left(u_{1} u_{2}\right)=f^{*}\left(u_{2} u_{3}\right)=q-1
$$

Figure 2 shows the method of edge odd graceful labeling of the path $\mathrm{P}_{3}$

This completes the proof.

1

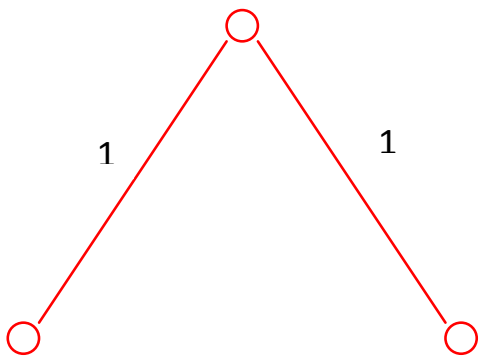

0

Fig 2

Theorem 3: $P_{n}$ is edge odd graceful for every integer $n \geq 2$.

Proof:

Let $\mathrm{V}\left(\mathrm{P}_{4}\right)=\left\{\mathrm{u}_{1}, \mathrm{u}_{2}, \mathrm{u}_{3}, \mathrm{u}_{4}\right\}$ where $\mathrm{V}\left(\mathrm{P}_{4}\right)$ is the vertex set of the path $\mathrm{P}_{4}$. For every vertex $u_{i}$, the edge odd graceful labeling functions $\mathrm{f}\left(\mathrm{u}_{\mathrm{i}}\right)$ is defined as follows.

$$
\mathrm{f}\left(\mathrm{u}_{1}\right)=0 ; \mathrm{f}\left(\mathrm{u}_{2}\right)=\mathrm{q}-2 ; \mathrm{f}\left(\mathrm{u}_{3}\right)=\mathrm{q}-1 ; \mathrm{f}\left(\mathrm{u}_{4}\right)=\mathrm{q}
$$

The edge labeling function $\mathrm{f}^{*}$ is defined as follows

$$
\mathrm{f}^{*}\left(\mathrm{u}_{1} \mathrm{u}_{2}\right)=\mathrm{f}^{*}\left(\mathrm{u}_{3} \mathrm{u}_{4}\right)=\mathrm{q}-2=\mathrm{f}^{*}\left(\mathrm{u}_{2} \mathrm{u}_{3}\right)
$$

Figure 3 shows the method of edge odd graceful labeling of the path $\mathrm{P}_{4}$

This completes the proof.

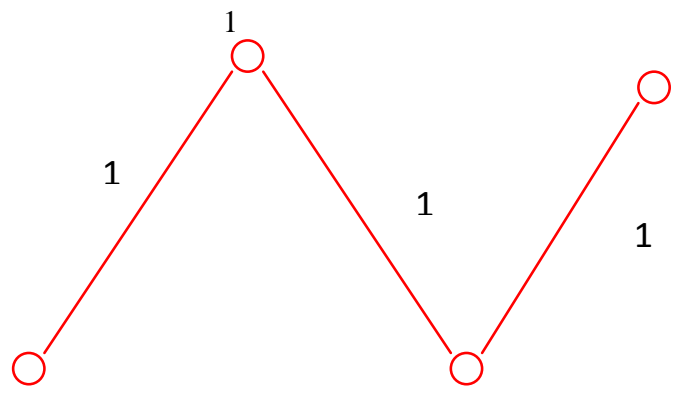

0

2

Fig 3

Theorem 4: $P_{n}$ is edge odd graceful for every integer $n \geq 2$.

Proof:
Let $\mathrm{V}\left(\mathrm{P}_{5}\right)=\left\{\mathrm{u}_{1}, \mathrm{u}_{2}, \mathrm{u}_{3}, \mathrm{u}_{4}, \mathrm{u}_{5}\right\}$ where $\mathrm{V}\left(\mathrm{P}_{5}\right)$ is the vertex set of the path $\mathrm{P}_{5}$. For every vertex $\mathrm{u}_{\mathrm{i}}$, the edge odd graceful labeling functions $\mathrm{f}\left(\mathrm{u}_{\mathrm{i}}\right)$ is defined as follows.

$\mathrm{f}\left(\mathrm{u}_{5}\right)=\mathrm{q}-3$;

$$
\mathrm{f}\left(\mathrm{u}_{1}\right)=\mathrm{q}+1 ; \mathrm{f}\left(\mathrm{u}_{2}\right)=\mathrm{q} ; \mathrm{f}\left(\mathrm{u}_{3}\right)=\mathrm{q}-3 ; \mathrm{f}\left(\mathrm{u}_{4}\right)=\mathrm{q}-2 ;
$$

The edge labeling function $\mathrm{f}^{*}$ is defined as follows.

$$
\mathrm{f}^{*}\left(\mathrm{u}_{1} \mathrm{u}_{2}\right)=\mathrm{f}^{*}\left(\mathrm{u}_{3} \mathrm{u}_{4}\right)=\mathrm{q}-3=\mathrm{f} *\left(\mathrm{u}_{4} \mathrm{u}_{5}\right) ; \mathrm{f} *\left(\mathrm{u}_{2} \mathrm{u}_{3}\right)=\mathrm{q}-1 ;
$$

Figure 4 shows the method of edgeodd graceful labeling of the graph $\mathrm{P}_{5}$

This completes the proof.

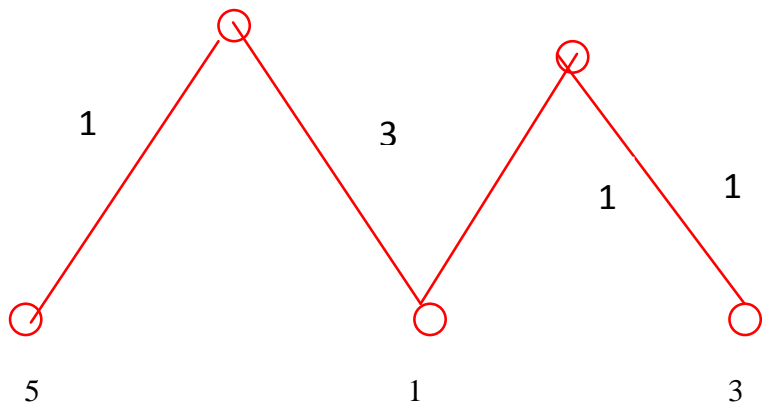

Fig 4

Theorem 5: $P_{n}$ is edge odd graceful for every integer $n \geq 2$.

Proof:

Let $\mathrm{V}\left(\mathrm{P}_{6}\right)=\left\{\begin{array}{lllll}\mathrm{u}_{1}, \mathrm{u}_{2} & \mathrm{u}_{3}, \mathrm{u}_{4}, \mathrm{u}_{5}, \mathrm{u}_{6}\end{array}\right\}$ where $\mathrm{V}\left(\mathrm{P}_{6}\right)$ is the vertex set of the path $\mathrm{P}_{6}$. For every vertex $\mathrm{u}_{\mathrm{i}}$, the edge odd graceful labeling functions $\mathrm{f}\left(\mathrm{u}_{\mathrm{i}}\right)$ is defined as follows.

$\mathrm{f}\left(\mathrm{u}_{1}\right)=0 ; \mathrm{f}\left(\mathrm{u}_{2}\right)=\mathrm{q} ; \mathrm{f}\left(\mathrm{u}_{3}\right)=\mathrm{q}-1 ; \mathrm{f}\left(\mathrm{u}_{4}\right)=\mathrm{q}-4 ;$

$\mathrm{f}\left(\mathrm{u}_{5}\right)=\mathrm{q}-3 ; \quad \mathrm{f}\left(\mathrm{u}_{6}\right)=\mathrm{q}-2$

The edge labeling function $\mathrm{f}^{*}$ is defined as follows.

$f^{*}\left(u_{1} u_{2}\right)=q ; f *\left(u_{3} u_{4}\right)=q-2 ; f *\left(u_{2} u_{3}\right)=f *\left(u_{4} u_{5}\right)=$ $\mathrm{f}^{*}\left(\mathrm{u}_{5} \mathrm{u}_{6}\right)=\mathrm{q}-4$

Figure 5 shows the method of edge odd graceful labeling of the path $\mathrm{P}_{6}$

This completes the proof. 


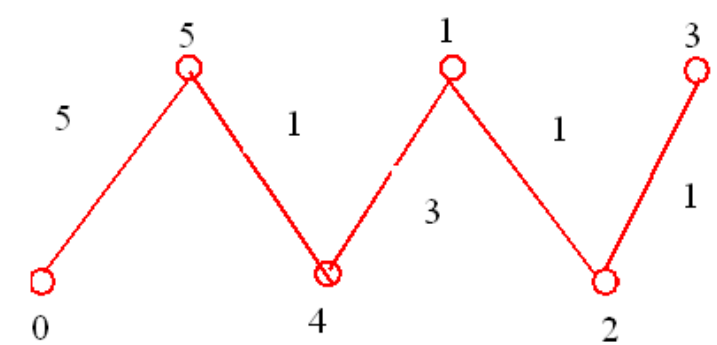

Fig 5

Theorem 6: $P_{n}$ is edge odd graceful for every integer $n \geq 2$.

Proof:

Let $\mathrm{V}\left(\mathrm{P}_{7}\right)=\left\{\mathrm{u}_{1}, \mathrm{u}_{2}, \mathrm{u}_{3}, \mathrm{u}_{4}, \mathrm{u}_{5}, \mathrm{u}_{6}, \mathrm{u}_{7}\right\}$ where $\mathrm{V}\left(\mathrm{P}_{7}\right)$ is the vertex set of the path $P_{7}$. For every vertex $u_{i}$, the edge odd graceful labeling functions $f\left(u_{i}\right)$ is defined as follows.

$$
\begin{aligned}
& \mathrm{f}\left(\mathrm{u}_{1}\right)=0 ; \mathrm{f}\left(\mathrm{u}_{2}\right)=\mathrm{q}+1 ; \mathrm{f}\left(\mathrm{u}_{3}\right)=\mathrm{q}-4 ; \mathrm{f}\left(\mathrm{u}_{4}\right)=\mathrm{q}-3 ; \\
& \mathrm{f}\left(\mathrm{u}_{5}\right)=\mathrm{q}-2 ; \quad \mathrm{f}\left(\mathrm{u}_{6}\right)=\mathrm{q}-1 ; \mathrm{f}\left(\mathrm{u}_{7}\right)=\mathrm{q}+2
\end{aligned}
$$

The edge labeling function $\mathrm{f}^{*}$ is defined as follows

$$
\begin{gathered}
f *\left(u_{1} u_{2}\right)=q+1 ; f *\left(u_{2} u_{3}\right)=q-1 \\
f *\left(u_{3} u_{4}\right)=f *\left(u_{4} u_{5}\right)=f *\left(u_{5} u_{6}\right)=q-5 ; f *\left(u_{6} u_{7}\right)=q-3
\end{gathered}
$$

Figure 6 shows the method of edge odd graceful labeling of the path $\mathrm{P}_{7}$

This completes the proof.

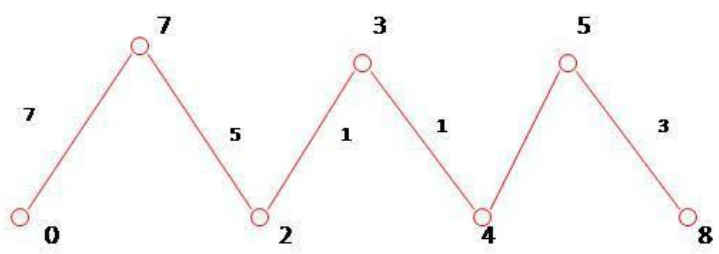

Fig 6

Theorem 7: $P_{n}$ is edge odd graceful for every integer $n \geq 2$.

Proof:

Let $\mathrm{V}\left(\mathrm{P}_{8}\right)=\left\{\mathrm{u}_{1}, \mathrm{u}_{2}, \mathrm{u}_{3}, \mathrm{u}_{4}, \mathrm{u}_{5}, \mathrm{u}_{6}, \mathrm{u}_{7}, \mathrm{u}_{8}\right\}$ where $\mathrm{V}\left(\mathrm{P}_{8}\right)$ is the vertex set of the path $P_{8}$. For every vertex $u_{i}$, the edge odd graceful labeling functions $f\left(u_{i}\right)$ is defined as follows.

$$
\begin{gathered}
\mathrm{f}\left(\mathrm{u}_{1}\right)=0 ; \mathrm{f}\left(\mathrm{u}_{2}\right)=\mathrm{q}+2 ; \mathrm{f}\left(\mathrm{u}_{3}\right)=\mathrm{q}-5 ; \mathrm{f}\left(\mathrm{u}_{4}\right)=\mathrm{q} ; \\
\mathrm{f}\left(\mathrm{u}_{5}\right)=\mathrm{q}-1 ; \mathrm{f}\left(\mathrm{u}_{6}\right)=\mathrm{q}-2 ; \mathrm{f}\left(\mathrm{u}_{7}\right)=\mathrm{q}-3 ; \mathrm{f}\left(\mathrm{u}_{8}\right)=\mathrm{q}-6
\end{gathered}
$$

The edge labeling function $\mathrm{f}^{*}$ is defined as follows.

$$
\begin{gathered}
\mathrm{f}^{*}\left(\mathrm{u}_{1} \mathrm{u}_{2}\right)=\mathrm{q}+2 ; \mathrm{f}^{*}\left(\mathrm{u}_{2} \mathrm{u}_{3}\right)=\mathrm{q} ; \mathrm{f} *\left(\mathrm{u}_{3} \mathrm{u}_{4}\right)=\mathrm{q}-2 ; \\
\mathrm{f}^{*}\left(\mathrm{u}_{4} \mathrm{u}_{5}\right)=\mathrm{f}^{*}\left(\mathrm{u}_{5} \mathrm{u}_{6}\right)=\mathrm{f}^{*}\left(\mathrm{u}_{6} \mathrm{u}_{7}\right)=\mathrm{q}-6 ; \mathrm{f}^{*}\left(\mathrm{u}_{7} \mathrm{u}_{8}\right)=\mathrm{q}-4
\end{gathered}
$$

Figure 7 shows the method of edge odd graceful labeling of the path $\mathrm{P}_{8}$.

This completes the proof.

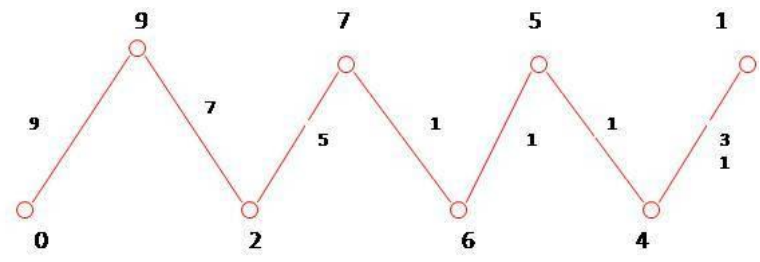

Fig 7

Theorem 8: $P_{n}$ is edge odd graceful for every integer $n \geq 2$.

Proof:

Let $\mathrm{V}\left(\mathrm{P}_{9}\right)=\left\{\mathrm{u}_{1}, \mathrm{u}_{2}, \mathrm{u}_{3}, \mathrm{u}_{4}, \mathrm{u}_{5}, \mathrm{u}_{6}, \mathrm{u}_{7}, \mathrm{u}_{8}, \mathrm{u}_{9}\right\}$ where $\mathrm{V}\left(\mathrm{P}_{9}\right)$ is the vertex set of the path $P_{9}$. For every vertex $u_{i}$, the edge odd graceful labeling functions $f\left(u_{i}\right)$ is defined as follows.

$$
\begin{aligned}
& \quad \mathrm{f}\left(\mathrm{u}_{1}\right)=0 ; \mathrm{f}\left(\mathrm{u}_{2}\right)=2 \mathrm{q}+5 ; \mathrm{f}\left(\mathrm{u}_{3}\right)=\mathrm{q}+4 ; \mathrm{f}\left(\mathrm{u}_{4}\right)=\mathrm{q}-3 ; \\
& \mathrm{f}\left(\mathrm{u}_{5}\right)=\mathrm{q}+2 ; \mathrm{f}\left(\mathrm{u}_{6}\right)=\mathrm{q}+3 ; \mathrm{f}\left(\mathrm{u}_{7}\right)=\mathrm{q} ; \mathrm{f}\left(\mathrm{u}_{8}\right)=\mathrm{q}-1 ; \mathrm{f}\left(\mathrm{u}_{9}\right) \\
& =\mathrm{q}-2
\end{aligned}
$$

The edge labeling function $\mathrm{f}^{*}$ is defined as follows.

$$
\begin{gathered}
f^{*}\left(\mathrm{u}_{1} \mathrm{u}_{2}\right)=2 \mathrm{q}+5 ; \mathrm{f}^{*}\left(\mathrm{u}_{2} \mathrm{u}_{3}\right)=\mathrm{q}+1: \mathrm{f}^{*}\left(\mathrm{u}_{3} \mathrm{u}_{4}\right)=\mathrm{q}-1 ; \\
\mathrm{f}^{*}\left(\mathrm{u}_{4} \mathrm{u}_{5}\right)=\mathrm{q}-3 ; \mathrm{f}^{*}\left(\mathrm{u}_{5} \mathrm{u}_{6}\right)=\mathrm{f}^{*}\left(\mathrm{u}_{8} \mathrm{u}_{9}\right)=\mathrm{f}^{*}\left(\mathrm{u}_{7} \mathrm{u}_{8}\right)=\mathrm{q}-7 ; \\
\mathrm{f}^{*}\left(\mathrm{u}_{6} \mathrm{u}_{7}\right)=\mathrm{q}-5
\end{gathered}
$$

Figure 8 shows the method of edge odd graceful labeling of the path $\mathrm{P}_{9}$

This completes the proof.

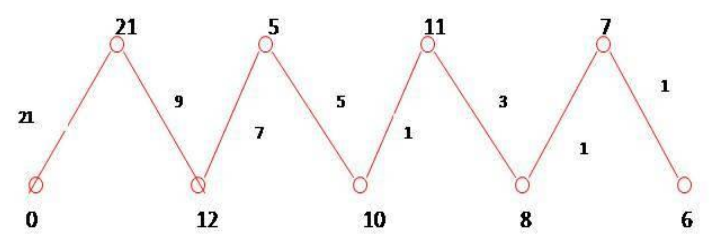

Fig 8

Theorem 9: $P_{n}$ is edge odd graceful for every integer $n \geq 2$.

Proof:

Let $\mathrm{V}\left(\mathrm{P}_{10}\right)=\left\{\mathrm{u}_{1}, \mathrm{u}_{2}, \mathrm{u}_{3}, \mathrm{u}_{4}, \mathrm{u}_{5}, \mathrm{u}_{6}, \mathrm{u}_{7}, \mathrm{u}_{8}, \mathrm{u}_{9}, \mathrm{u}_{10}\right\}$ where $\mathrm{V}\left(\mathrm{P}_{10}\right)$ is the vertex set of the path $P_{10}$. For every vertex $u_{i}$, the edge odd graceful labeling functions $\mathrm{f}\left(\mathrm{u}_{\mathrm{i}}\right)$ is defined as follows.

$$
f\left(u_{1}\right)=0 ; f\left(u_{2}\right)=4 q+1 ; f\left(u_{3}\right)=2 q-2 ; f\left(u_{4}\right)=2 q+5 ;
$$




$$
\begin{gathered}
f\left(u_{5}\right)=2 q-4 ; f\left(u_{6}\right)=q+2 ; f\left(u_{7}\right)=q+1 ; f\left(u_{8}\right)=q-2 ; \\
f\left(u_{9}\right)=q-1 ; f\left(u_{10}\right)=q
\end{gathered}
$$

The edge labeling function $\mathrm{f}^{*}$ is defined as follows.

$$
\begin{aligned}
& f^{*}\left(u_{1} u_{2}\right)=4 q+1 ; f^{*}\left(u_{2} u_{3}\right)=2 q+3 ; f^{*}\left(u_{3} u_{4}\right)=q-2 ; \\
& f^{*}\left(u_{4} u_{5}\right)=q ; f^{*}\left(u_{5} u_{6}\right)=q-4 ; f^{*}\left(u_{6} u_{7}\right)=f^{*}\left(u_{8} u_{9}\right)= \\
& f^{*}\left(u_{9} u_{10}\right)=q-8 \\
& f^{*}\left(u_{7} u_{8}\right)=q-6 ;
\end{aligned}
$$

Figure 9 shows the method of edge odd graceful

$$
\text { labeling of the path } \mathrm{P}_{10}
$$

This completes the proof.

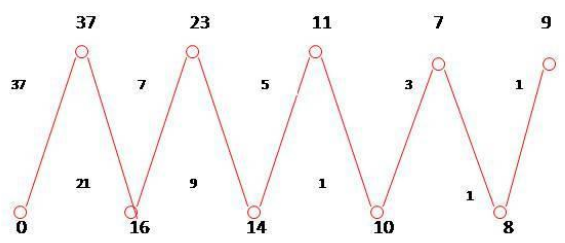

Fig 9

Theorem 10: $P_{n}$ is edge odd graceful for every integer $n \geq 2$.

Proof:

Let $\mathrm{V}\left(\mathrm{P}_{11}\right)=\left\{\mathrm{u}_{1}, \mathrm{u}_{2}, \mathrm{u}_{3}, \mathrm{u}_{4}, \mathrm{u}_{5}, \mathrm{u}_{6}, \mathrm{u}_{7}, \mathrm{u}_{8}, \mathrm{u}_{9}, \mathrm{u}_{10}, \mathrm{u}_{11}\right\}$ where $\mathrm{V}\left(\mathrm{P}_{11}\right)$ is the vertex set of the path $\mathrm{P}_{11}$. For every vertex $u_{i}$, the edge odd graceful labeling functions $f\left(u_{i}\right)$ is defined as follows.

$\mathrm{f}\left(\mathrm{u}_{1}\right)=0 ; \mathrm{f}\left(\mathrm{u}_{2}\right)=5 \mathrm{q}-1 ; \mathrm{f}\left(\mathrm{u}_{3}\right)=\mathrm{q}+2 ; \mathrm{f}\left(\mathrm{u}_{4}\right)=3 \mathrm{q}+3 ;$ $\mathrm{f}\left(\mathrm{u}_{5}\right)=2 \mathrm{q}+4 ; \mathrm{f}\left(\mathrm{u}_{6}\right)=\mathrm{q}+7 ; \mathrm{f}\left(\mathrm{u}_{7}\right)=2 \mathrm{q}+2 ; \mathrm{f}\left(\mathrm{u}_{8}\right)=2 \mathrm{q}+5 ;$

$$
f\left(u_{9}\right)=2 q+6 ; f\left(u_{10}\right)=2 q+7 ; f\left(u_{11}\right)=2 q+8
$$

The edge labeling function $\mathrm{f}^{*}$ is defined as follows.

$$
\begin{aligned}
& \mathrm{f}^{*}\left(\mathrm{u}_{1} \mathrm{u}_{2}\right)=5 \mathrm{q}-1 ; \mathrm{f}^{*}\left(\mathrm{u}_{2} \mathrm{u}_{3}\right)=3 \mathrm{q}+7 ; \mathrm{f}^{*}\left(\mathrm{u}_{3} \mathrm{u}_{4}\right)=2 \mathrm{q}+1 ; \\
& \mathrm{f}^{*}\left(\mathrm{u}_{4} \mathrm{u}_{5}\right)=\mathrm{q}-1 ; \mathrm{f}^{*}\left(\mathrm{u}_{5} \mathrm{u}_{6}\right)=\mathrm{q}-3 ; \mathrm{f}^{*}\left(\mathrm{u}_{6} \mathrm{u}_{7}\right)=\mathrm{q}-5 ; \\
& \mathrm{f}^{*}\left(\mathrm{u}_{7} \mathrm{u}_{8}\right)=\mathrm{q}-7 ; \mathrm{f}^{*}\left(\mathrm{u}_{8} \mathrm{u}_{9}\right)=\mathrm{f}^{*}\left(\mathrm{u}_{9} \mathrm{u}_{10}\right)=\mathrm{f}^{*}\left(\mathrm{u}_{10} \mathrm{u}_{11}\right)=\mathrm{q}-9
\end{aligned}
$$

Figure 10 shows the method of edge odd graceful labeling of the path graph $\mathrm{P}_{11}$.

This completes the proof.

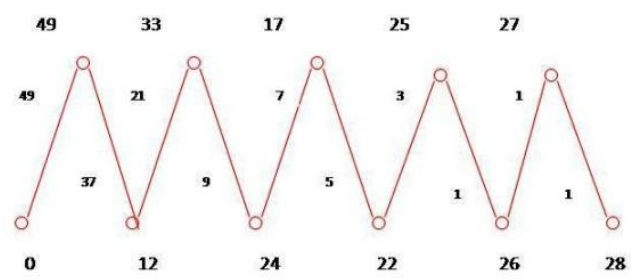

Fig 10

Theorem 11: $P_{n}$ is edge odd graceful for every integer $n \geq 2$.

Proof:

Let $\mathrm{V}\left(\mathrm{P}_{12}\right)=\left\{\mathrm{u}_{1}, \mathrm{u}_{2}, \mathrm{u}_{3}, \mathrm{u}_{4}, \mathrm{u}_{5}, \mathrm{u}_{6}, \mathrm{u}_{7}, \mathrm{u}_{8}, \mathrm{u}_{9}, \mathrm{u}_{10}, \mathrm{u}_{11}, \mathrm{u}_{12}\right\}$ where $\mathrm{V}\left(\mathrm{P}_{12}\right)$ is the vertex set of the path $\mathrm{P}_{12}$. For every vertex $\mathrm{u}_{\mathrm{i}}$, the edge odd graceful labeling functions $\mathrm{f}\left(\mathrm{u}_{\mathrm{i}}\right)$ is defined as follows.

$$
\mathrm{f}\left(\mathrm{u}_{1}\right)=0 ; \mathrm{f}\left(\mathrm{u}_{2}\right)=6 \mathrm{q}-1 ; \mathrm{f}\left(\mathrm{u}_{3}\right)=\mathrm{q}+5 ; \mathrm{f}\left(\mathrm{u}_{4}\right)=5 \mathrm{q}-2 ;
$$
$2 q+3$

$$
\mathrm{f}\left(\mathrm{u}_{5}\right)=3 \mathrm{q}-1 ; \mathrm{f}\left(\mathrm{u}_{6}\right)=2 \mathrm{q}+1 ; \mathrm{f}\left(\mathrm{u}_{7}\right)=3 \mathrm{q}-3 ; \mathrm{f}\left(\mathrm{u}_{8}\right)=
$$

$f\left(u_{9}\right)=2 q ; f\left(u_{10}\right)=2 q-1 ; f\left(u_{11}\right)=2 q-2 ; f\left(u_{12}\right)=2 q$

The edge labeling function $\mathrm{f}^{*}$ is defined as follows.

$$
\begin{gathered}
\mathrm{f}^{*}\left(\mathrm{u}_{1} \mathrm{u}_{2}\right)=6 \mathrm{q}-1 ; \mathrm{f}^{*}\left(\mathrm{u}_{2} \mathrm{u}_{3}\right)=4 \mathrm{q}+5 ; \mathrm{f}^{*}\left(\mathrm{u}_{3} \mathrm{u}_{4}\right)=3 \mathrm{q}+4 ; \\
\mathrm{f} *\left(\mathrm{u}_{4} \mathrm{u}_{5}\right)=2 \mathrm{q}-1 ; \mathrm{f}^{*}\left(\mathrm{u}_{5} \mathrm{u}_{6}\right)=\mathrm{q}-2 ; \mathrm{f}^{*}\left(\mathrm{u}_{6} \mathrm{u}_{7}\right)=\mathrm{q}-4 ; \\
\mathrm{f}\left(\mathrm{u}_{7} \mathrm{u}_{8}\right)=\mathrm{q}-6 ; \\
\quad \mathrm{f}^{*}\left(\mathrm{u}_{8} \mathrm{u}_{9}\right)=\mathrm{q}-8 ; \mathrm{f}^{*}\left(\mathrm{u}_{9} \mathrm{u}_{10}\right)=\mathrm{f} *\left(\mathrm{u}_{10} \mathrm{u}_{11}\right)=\mathrm{f}^{*}\left(\mathrm{u}_{11} \mathrm{u}_{12}\right) \\
=\mathrm{q}-10
\end{gathered}
$$

Figure 10 shows the method of edge odd graceful

$$
\text { labeling of the path graph } \mathrm{P}_{11} \text {. }
$$

This completes the proof.

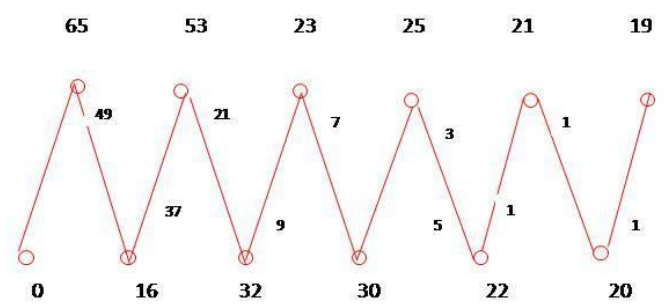

Fig 11

\section{CONCLUSION}

In all the above paths, we can see that the edges are labeled with odd numbers and hence they are said to be edge - odd graceful. Also, we can also see that the odd vertices are labeled with even numbers and the even vertices are labeled with odd numbers.

\section{ACKNOWLEDGEMENTS}

The author is very thankful to the experts who have contributed towards the development of this article and their kind suggestions.

\section{REFERENCES}

[1] R.B. Gnanajothi, Topics in Graph Theory,Ph.D.Thesis, Madurai Kamaraj University, 1991

[2] G.J.Gallian, A dynamic survey of graph labeling, The electronic journal of combinatorics, 16 (2009), \#DS6. 
[3] S.W. Golomb, How to number a graph in graph theory and computing, R.C. Read, ed., Academic Press, New York (1972), 23-37.

[4] A. Rosa, On certain valuations of the vertices of a graph, Theory of graphs(International Symposium, Rome), July(1966)
[5] S. Uma Maheswari, Graceful Labeling of the paths using padavon sequence, International Journal of Mathematical Archive-4(4), 013, 66-71.

[6] S. Uma Maheswari, Even Graceful Labeling of the paths using padavon sequence, International Journal of Mathematical Archive-4(10), To appear. 